\title{
Insurgência e conservadorismo: considerações sobre o paradoxo da cidadania no Brasil
}

Insurgency and conservatism: considerations on the paradox of citizenship in Brazil

\section{Marcelo Martins da Silva*}

\begin{abstract}
Resumo - A cidadania no Brasil sempre foi marcada por avanços, retrocessos e diferenciação no grau de participação e usufruto dos direitos que lhe são pertinentes pelas diferentes classes sociais. A cidadania insurgente, que é, segundo James Holston, trata-se de uma categoria global de análise, aparece como uma ferramenta política importante para a luta por direitos das populações mais pobres, principalmente aqueles que dizem respeito a reprodução da vida cotidiana. Dessa forma, partindo do trabalho de Holston sobre o conceito de cidadania insurgente, este artigo pretende discorrer sobre a cidadania insurgente no Brasil, reconhecendo sua potencialidade e problematizando seus limites.
\end{abstract}

Palavras-Chave: cidadania; insurgência; conservadorismo; conflito.

\begin{abstract}
Citizenship in Brazil has always been marked by advances, setbacks and differentiation in the degree of participation and usufruct of the rights that are pertinent to it by different social classes. Insurgent citizenship is, according to James Holston, a global category of analysis. It appears as an important political tool for the struggle for rights of the poorest populations, especially those that concern the reproduction of everyday life. Thus, based on Holston's work on the concept of insurgent citizenship, this article aims to discuss insurgent citizenship in Brazil, recognizing its potentiality and problematizing its limits.

Keywords: citizenship; insurgency; conservatism; conflict.
\end{abstract}

\section{Introdução}

A noção de cidadania não possui um sentido único, tampouco apenas positivo ou negativo. Na Antiguidade, cidadania dizia respeito a

\footnotetext{
* Mestre em Planejamento e Gestão do Território pela Universidade Federal do ABC (UFABC). Sociólogo pela Prefeitura Municipal de Mauá e Pesquisador pelo grupo de pesquisa Política, Políticas Públicas e Ação Coletiva (3PAC), vinculado à UFABC. Correspondência: Rua Rodrigo Otávio, 64 - Jardim Santo Alberto - Santo André São Paulo. CEP: 09260-300. Email: <marcelo-msilva@bol.com.br>.
} 


\section{ReVistg aाm paltg}

\} INSURGÊNCIA E CONSERVADORISMO - SILVA, M. S. \}

DOI 10.12957/REP.2017.30377

privilégios estamentais, discriminando os estamentos considerados inferiores. "Cidadão" remetia a uma condição privilegiada, restrita a poucos. Com o advento da modernidade, do capitalismo, das classes sociais e de uma sociedade contratualista, em que o pressuposto passa ser o de que todos são iguais perante a lei (pelo menos no Ocidente), "cidadania" e "cidadão" ganharam status formal, legal. Contudo, na prática, a forma de objetivação da cidadania varia conforme o momento histórico, a formação social e a relação entre esses elementos e a produção e reprodução da vida material.

As variações da cidadania podem ser resumidas abstratamente em duas: uma formal, isto é, fazer parte de uma comunidade política; e outra substantiva, que significa ter acesso a diretos (civis, políticos e sociais) que devem estar disponíveis. As duas formas de cidadania não se excluem mutualmente; pelo contrário, se confundem e são objeto de disputa. A primeira, a relação entre indivíduo e Estado, remete a privilégios na medida em que normatiza e universaliza as relações sociais, encapsulando-as em um sistema de proteção que requer obediência. Neste sentido, tudo aquilo que está fora da norma, da "ordem", deve ser repreendido e, consequentemente, normatizado, ainda que a situação concreta mostre o contrário. Portanto, aqueles que detêm uma situação privilegiada e possuem influência no Estado e na definição daquilo que vai ser ou não "cidadania", agem segundo seus interesses para a manutenção de privilégios.

A cidadania substantiva relaciona-se com o concreto, o efetivo, isto é, determina o cidadão como uma pessoa dotada de direitos e que age para a objetivação desses direitos, ainda que na contramão da cidadania formal (SOARES, 2009, p. 131-132). É uma construção histórica e, a nosso ver, antítese da cidadania formal, na medida em que busca tornar em prática aquilo que é universal na teoria, por meio da participação popular, articulada ou não em grupos de afinidade (classe, gênero, grupos étnico-raciais, etc.).

Nos limites deste trabalho, pretendemos discorrer brevemente sobre as possibilidades de uma cidadania substantiva - cujos autores, como James Holston (1996, 2009, 2013) e Carlos Vainer (2011), designam como "cidadania insurgente" - nos centros urbanos brasileiros, levando em conta fatores estruturantes como o território (THERBORN, 2011, 2014), a relação entre política e economia em uma sociedade (OLIVEIRA, 2007) e o modelo de Estado e sua relação com a sociedade civil (HARVEY, 2006).

O artigo está estruturado em quatro seções: a primeira trata da potencialidade política da cidadania insurgente nos centros urbanos e sua validade como categoria de análise; a segunda problematiza a subcidadania como um dos possíveis pressupostos que faz emergir a cidadania insurgente nas classes mais pobres; a terceira aponta para seus limites estruturantes: subsunção da política pela economia e o Estado capitalista; na quarta e última seção faremos algumas considerações finais. 


\section{A cidadania insurgente: potencialidades}

As democracias que hoje caracterizam vários países do Hemisfério Sul (dentre eles o Brasil) não foram suficientes para garantir à grande massa da população acesso aos direitos ou à riqueza social produzida de forma igualitária. A industrialização do Pós-Guerra e a crise do capital nos países centrais, que transferiu parte da produção para países periféricos, promoveram desenvolvimento econômico nesses países. No entanto, a questão é que essa produção não foi acompanhada por desenvolvimento social compatível. Produziu-se valor, gerou-se riqueza, mas não houve fruição desta por parte da maioria da população, já que o que caracterizou a transferência da produção foi a oferta de mão de obra barata, ou seja, um aprofundamento da exploração do trabalho.

James Holston (2009, p. 245) aponta que há um enorme alcance da urbanização e da globalização em âmbito mundial, principalmente após os anos de 1970. Porém, seus efeitos, combinados com particularidades locais, geraram condições semelhantes em todo mundo: periferias urbanas com uma população pobre e explorada em condições de residência ilegal e irregular. Foi justamente nestes espaços periféricos que surgiu aquilo que o autor denomina de "cidadanias insurgentes", encarnadas em movimentos de contraposição e resistência às desigualdades a que estão submetidos. $\mathrm{O}$ elemento simbólico e espacial contra o qual e onde resistir passa a ser o centro urbano e, mesmo não sendo regra, já que não foram em todas as periferias que surgiram esses conflitos, é possível qualificar a cidadania insurgente como categoria global de conflito.

Este conflito se corporifica na contradição entre as promessas de uma sociedade mais justa e digna e a prática que aponta para desigualdades e marginalizações, tendo gerado resistência aos privilégios com formas alternativas de cidadania para além da idiossincrasia ou instrumentalidade. Ou seja, há um nexo social e moral que baliza os confrontos para além da percepção individual ou da vida imediata (diferente aqui de vida cotidiana). Esse nexo é a noção de "direitos" ou "direito à cidade", embutida em protestos que utilizam o centro urbano como marco simbólico da esfera pública oficial (HOLSTON, 2009, p. 246).

Porém, argumenta o autor (HOLSTON, 2009, p. 247-248), não é na praça cívica (centro) que os pobres urbanos articulam essa demanda com maior força e originalidade (este seria um segundo momento), mas sim no cotidiano e na vida doméstica em torno da construção da residência. Os líderes e soldados destes movimentos são pessoas comuns que vivem uma vida precária e lutam por seus espaços residenciais e por outra forma de cidadania que não a oficial e formal. Essa "outra" cidadania tem relação particularmente com os pobres do Hemisfério Sul e visa muito mais à resistência e aos recursos básicos cotidianos do que às reivindicações da classe trabalhadora europeia no século passado. Essa concepção está apoiada em 


\section{meVistg am paltg}

\} INSURGÊNCIA E CONSERVADORISMO - SILVA, M. S. \}

DOI $10.12957 /$ REP.2017.30377

Lefebvre (2006), em sua visão do "direito à cidade" como emergente da luta pela vida cotidiana dos pobres. Isto é, a luta transfere-se da "produção" para a "reprodução", o que vale dizer que a tomada e o controle dos meios de produção não são mais o foco, já que este se transfere para a qualidade de vida'.

As transformações urbanas no Brasil, especialmente a partir de 1970, quando as pessoas foram atraídas para os centros urbanos devido à industrialização acelerada, traduziram-se em precariedade habitacional. Isso porque os centros das cidades, projetados para representarem capitais modernizadoras, não poderiam, segundo a elite, alocar os trabalhadores que chegavam para trabalhar nas fábricas. Assim, sobraram regiões distantes e sem infraestrutura; além disso, devido aos baixos salários, vigorava a precariedade, a ilegalidade e a possibilidade de:

[...] construir suas próprias casas, se organizar para conseguir serviços básicos e lutar para manter suas casas em meio a diversos conflitos, frequentemente violentos, pela propriedade dos imóveis. Ainda assim, em algumas décadas eles urbanizaram esses bairros e melhoraram de forma notável suas condições de vida. (HOLSTON, 2013, p. 29).

A engenhosidade da população faz com que desses lugares flua criatividade para adaptações e estratégias que renovem a vida diária. A aglutinação dessa criatividade se corporifica em movimentos de cidadania insurgente e redefinem a cidadania urbana em termos de acesso a recursos.

Esse "desestranhamento" - em termos marxianos, reconhecimento das condições de vida -, a partir do lugar, relaciona-se com aquilo que Therborn (2011, p. 500) tratou de "positive potencial of place". O lugar, segundo o autor, molda e dá significado para a ação dos atores sociais. Neste sentido, é causa e resultado da ação:

In other words, place is both a crucial explanatory or 'independent' variable, an 'intermediary' variable of setting or 'locale' [...] and a significant 'dependent' variable. Place is thus an example of the dialectics of structure and agency. (THERBORN, 2011, p. 501).

Essa dialética entre agência e estrutura faz com que o lugar a partir do qual se formam os atores da "cidadania insurgente", as periferias urbanas autoconstruídas, seja o lócus dos conflitos e resistências. É nas periferias, principalmente, que se dão os conflitos por posse de terra, que o braço armado e repressivo do Estado (a polícia) age na manutenção da resistência reacionária (o "entrincheirado" segundo James Holston - 2013), e que a violência gera identidade, ressignificação cultural e resistência.

As periferias urbanas não foram, portanto, lugares escolhidos para serem a residência dos trabalhadores. Foi o que sobrou, o possível em deter-

\footnotetext{
1 O capitalismo, neste sentido, como organizador das relações sociais, acaba sendo tomado como algo dado, que emerge das relações sociais, quando, a nosso ver, foi e é imposto reiteradamente.
} 
minado momento. Neste sentido, há uma mescla cultural de diversas origens que se aglutinam e redundam num caldo cultural que é a diversidade.

Vainer (2011) afirma a relevância de se compreender a diversidade no interior da luta de classes. Essas classes - gênero, raça, origem, etc. completam "[...] o quadro de exploração e dominação da sociedade burguesa, que não se resume nem é compreendido ou combatido apenas no nível da luta entre capital e trabalho" (VAINER, 2011, p. 17). É necessária certa precaução ao se tratar da diversidade para não cair em armadilhas reacionárias neoliberais, que se utilizam do conceito para justificar desigualdades, confundindo-as com diferenças:

Partindo disso, a diversidade é pensada não no lugar da desigualdade, mas como uma das outras tantas manifestações de desigualdade que a sociedade contemporânea impõe a grupos sociais específicos. Nessa perspectiva, queremos a legitimidade, o reconhecimento da importância da multiplicidade de formas de opressão e de resistência. O desafio é que o reconhecimento dessas múltiplas formas de resistência sejam utilizadas como instrumento de arregimentação para a luta contra as formas vigentes de dominação. (VAINER, 2011, p. 17).

A multiplicidade e a complexidade advindas da diversidade requerem um aprofundamento do debate entre os diversos atores de determinado lugar. Este debate se dá através da política, do conflito. Vainer (2011, p. 17) vê o conflito como o processo que questiona a cidade, sendo, portanto, criativo. A atribuição de "patologia social" ao conflito torna as questões sociais estéreis e suas contradições funcionais. Holston (1996, p. 248), ao fazer a crítica ao planejamento modernista, afirma que a questão fundamental não é o modernismo pressupor uma sociedade inexistente e sonhar com uma, mas, ao fazê-lo de forma funcional e normativa, não desenvolve produtivamente seus paradoxos, suas contradições:

Ao invés disso, ele tenta ser um plano sem contradição, sem conflitos [...] tal suposição tende a ser arrogante e falsa. Por um lado, ela não inclui elementos constitutivos do planejamento, o conflito, a ambiguidade e a indeterminação, característicos da vida social. Por outro, deixa de considerar o inintencional e o inesperado como partes do modelo. (HOLSTON, 1996, p. 248).

Neste sentido é que é possível afirmar a existência de uma "cidadania insurgente" nos centros urbanos brasileiros, a partir da perspectiva do conflito e da reorganização da classe trabalhadora em torno de outras demandas que não o controle dos meios de produção ${ }^{2}$. Assim, Therborn (2014) questiona: "[...] existe hoje alguma força social que poderia assumir o papel

\footnotetext{
2 É preciso salientar que, ainda que adormecida, a perspectiva do controle dos meios de produção por parte dos trabalhadores não definhou por completo; teleologicamente, permanece como possibilidade histórica para parte da militância anticapitalista.
} 


\section{meVistg am paltg}

\} INSURGÊNCIA E CONSERVADORISMO - SILVA, M. S. \}

DOI 10.12957/REP.2017.30377

da classe trabalhadora organizada ou dos movimentos anticolonialistas do século XX?". O autor mesmo responde que, se procurarmos forças anticapitalistas, certamente não, mas se procurarmos movimentos críticos à sociedade capitalista contemporânea há importantes forças sociais se manifestando.

De fato, parece que, com a queda do muro de Berlim e a ascensão da ideologia e prática neoliberal, o mercado foi reificado como instância de referência absoluta. Dessa forma, dificulta a emergência de movimentos que tenham por finalidade uma luta anticapitalista. A militância anticapitalista perde força ante a militância por direitos ou prerrogativas no interior do capitalismo. Entretanto, apesar disso, o autor vê quatro forças sociais importantes, limitadas pelo furor e influência do capital, mas que constituem a crítica mais fecunda à sociedade capitalista contemporânea:

[...] as populações pré-capitalistas, lutando para conservar seu território e seus meios de subsistência; as massas 'excedentes', excluídas do emprego formal nos circuitos da produção capitalista; os trabalhadores fabris explorados em todas as zonas ex-industriais decadentes e outras zonas empobrecidas; novas e antigas classes médias, cada vez mais oneradas com o pagamento de dívidas às corporações financeiras - estas constituem as possíveis bases sociais para as críticas contemporâneas à ordem capitalista dominante. O avanço exigirá, quase com certeza, alianças entre essas bases e, portanto, a articulação de seus interesses. Para qual caminho, ou quais caminhos, vai pender a nova classe média na África, Ásia e América Latina? Esse será um fator determinante e vital. (THERBORN, 2014).

Para o autor, o fiel da balança será a classe média, que, empobrecida, pode vir a ter um papel central na definição dos interesses populares ou das elites. Além disso, se vier a ficar ao lado das classes populares, seus valores e aspirações terão de ser respeitados e adequados às demandas populares de inclusão e igualdade.

Certamente esse seria um importante limitador para a afirmação da nossa questão central, a saber, as possibilidades de uma cidadania substantiva nos centros urbanos brasileiros. As classes médias no Brasil têm histórico conservador, sempre apoiaram movimentos repressivos e reacionários, como a ditadura de 1964-1985 e a eleição de Fernando Collor em 1989. As manifestações de junho de 2013 demonstraram uma cisão de demandas quando movimentos populares e partidos de esquerda foram hostilizados, em grande parte, pela classe média que resolveu se movimentar ${ }^{3}$.

Os interesses das classes médias no Brasil mais ou menos corroboraram com os interesses das elites. Contudo, quais os processos que essa sociedade, voltada para as elites, desenvolveu como forma de manter pri-

\footnotetext{
${ }^{3}$ Exceto por alguns daqueles inseridos na produção intelectual (professores, jornalistas, etc.), a classe média no Brasil tem sido contra as demandas populares mais radicais, como aquelas referentes à terra, às conquistas sindicais e aos direitos das populações menos abastadas.
} 
vilégios e segregação social? E qual o papel do Estado neste processo de limitação da cidadania insurgente (mais próxima da substantiva) no Brasil? Holston (2009, p. 255-256) argumenta que a persistência de uma cidadania diferenciada, inclusiva e desigual é o principal obstáculo para a cidadania insurgente. $\mathrm{O}$ autor faz uma regressão histórica para compreender o desenvolvimento desta nova forma de cidadania urbana. Observa que a cidadania no Brasil, no século XIX, era baseada nas diferenças para a gradação dos direitos, que, por sua vez, gerava desigualdade de condições e de acesso aos recursos públicos.

A estratégia de diferenciação que as elites criaram no final do século XIX foi o voto, negado aos analfabetos, perdurando por todo o século XX até 1985, quando tal restrição foi revogada. Durante todo o século XX permaneceu o paradigma da cidadania diferenciada, alimentando, sendo alimentada e sobrevivendo a cada regime político ao longo dos últimos duzentos anos. Prosperou sob a Monarquia, a Ditadura Militar e a democracia eleitoral. Sua capacidade metamórfica permitia a coexistência com a exclusão da propriedade (é possível ser cidadão e não ter seus direitos fundamentais de cidadão respeitados), a negação dos direitos políticos, a ilegalidade residencial, o servilismo, etc., e com certa igualdade jurídica, democracia eleitoral e algum nível de distribuição dos direitos sociais após a década de 1940.

Com o êxodo rural e o expediente de espaços autoconstruidos, a diferenciação gerou a contradição que alimentou a insurgência cidadã periférica. A cidadania diferenciada e as dificuldades dela advindas não domesticaram as classes populares; ao contrário, politizaram-nas (HOLSTON, 2009, p. 257).

A noção que as classes populares têm de suas demandas, parte de suas próprias experiências, e não de planos do governo ou do Estado. A participação ativa dos movimentos populares na Constituição de 1988 fez com que as pessoas se sentissem vinculadas ao documento, considerandoo um potencial para atender as suas demandas, até então sem nenhuma perspectiva teórica "oficial" que as representasse. Porém, a perspectiva desses direitos ainda tem um caráter híbrido, na medida em que imputa elementos morais a prerrogativas de direitos, ou seja, possui direito quem faz por onde, quem é honesto, etc. Ainda se mantém a noção conservadora dos direitos baseados em características individuais, e não como de alcance universal. Esse hibridismo torna a cidadania insurgente refém de práticas já arraigadas na tradição social brasileira e tendem à segmentação e à violência (HOLSTON, 2009, p. 261).

Para o autor, as desigualdades continuam no Brasil, mas a base cultural e política de sustentação dessas desigualdades estão desgastadas. De todo modo, no Brasil, a cidadania insurgente não foi o suficiente para interromper a cidadania diferenciada, mas manteve-se como elemento legítimo de inovação democrática: 


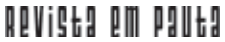

\} INSURGÊNCIA E CONSERVADORISMO - SILVA, M. S. \}

DOI 10.12957/REP.2017.30377

I conclude that although Brazil's democratization has not been able to overcome these problems, neither has the counter-configurations of violence and injustice been able to prevent the development of significant measures of democratic innovation. Above all, it has not prevented the widespread legitimation of an insurgent democratic citizenship. For the time being in Brazil, as in so many places, neither democracy nor its counters prevails. Rooted, they remain entangled, unexpectedly surviving each other. (HOLSTON, 2009, p. 263-264).

Holston (2009), entretanto, limita suas críticas às disrupções sociopolítico-econômicas no interior do capitalismo e as toma como algo dado, quase natural. Capitalismo e desigualdade essencialmente caminham juntos. Apesar disso, é possível um capitalismo com menor grau de injustiça social local, mas, se olharmos para além do local, um sistema baseado na exploração do trabalho vai, inevitavelmente, desenvolver sistemas de exploração, desigualdades, diferenciações etc., no interior de nações ou entre nações. Assim, o Estado, apesar de não ser simplesmente o comitê executivo dos negócios da burguesia, na correlação de forças é apropriado com base na violência e na diferenciação, legal ou não, pela parcela economicamente dominante. Há, de fato, pequenos ganhos intermitentes para as classes populares, mas dependendo da qualidade da relação entre as classes (e das relações sociais em geral) não há desenvolvimento social. Parte da resposta está na história e no desenvolvimento particular de determinada formação social, mas outra parte está nos elementos estruturantes do sistema capitalista que, no contexto brasileiro, produziu uma subcidadania.

\section{A subcidadania no Brasil}

As características da cidadania insurgente, como apresentadas por Holston, podem ser aproximadas do tripé de direitos referidos por T. H. Marshall (apud TAVOLARO; TAVOLARO, 2010, p. 339): civil, político e social. Aproxima-se dos direitos civis ao reivindicar o respeito aos direitos constitucionais dos cidadãos dos espaços periféricos; dos direitos políticos, porque é uma luta por justiça que envolve a participação política efetiva daqueles que têm pouca representatividade; e dos direitos sociais, na medida em que o direito à moradia é o norte, segundo Holston $(2009$, 2013), dos pobres urbanos, artífices da cidadania insurgente. De certo modo, portanto, a cidadania insurgente transcende as cidadanias civil, política e social; neste sentido, é de fato algo novo.

Sua excepcionalidade principal, no entanto, consiste no fato de que, por meio dela, as classes pobres lutam por seus direitos, enquanto as classes abastadas contemporâneas podem se dar ao luxo de usufruir desses direitos integralmente, num contexto democrático, dado que essa garantia se deu na História, muitas vezes às custas de violência contra as classes 
populares. Como essas garantias não foram estendidas a todos, o pressuposto das classes pobres é, portanto, a subcidadania, ou melhor, é na relação dialética com esta que insurge a noção de cidadania.

A subcidadania, segundo Souza (2003), decorre do fato de que as classes populares não estariam, historicamente, adaptados aos padrões políticos, jurídicos, culturais e econômicos emergentes da racionalidade ocidental moderna, esta, por si só, excludente. Essa análise da naturalização da desigualdade periférica, segundo o autor, abarca tanto países periféricos - como o Brasil - como países centrais, ainda que nestes os efeitos sejam menores. A especificidade da formação social brasileira, neste contexto, apesar de importante, não é fatal e imutável, pois é a dinâmica das classes sociais que determina o acesso, ou baixo grau de acesso, à cidadania formal por parte da população menos abastada, e não uma herança pré-moderna ou um essencialismo cultural personalista que independesse das classes.

Holston (2013) parece concordar com Souza (2003) sobre o fato de que não é o personalismo o indutor das mazelas sociais e de que a noção de cidadania insurgente (e consequentemente seu pressuposto: a subcidadania) pode ser definida como uma categoria global de conflito. No entanto, assim como o primeiro não problematiza a função de superexplorado do "subcidadão" no contexto da produção capitalista, remetendo à sua condição, sua inadaptação, Holston (2009) não problematiza a superexploração a que estão submetidos aqueles que fazem emergir a cidadania insurgente.

Os mecanismos da superexploração do trabalho ${ }^{4}$, segundo Ruy Mauro Marini (apud SANTANA, 2013, p. 23-24), podem ser resumidos em

três modalidades de apropriação do tempo de trabalho excedente por parte dos capitalistas, que podem ocorrer pela via da redução do preço da força de trabalho abaixo de seu valor: 1) o prolongamento da jornada de trabalho; 2) o aumento da intensidade do trabalho e 3) a conversão do fundo de consumo necessário do operário em fundo de acumulação do capital. A conjugação de uma ou mais dessas modalidades tornaria o salário (preço da força de trabalho) insuficiente para compensar um processo de trabalho que exija um desgaste físico e mental além do normal, o que implicaria a violação da lei do valor da força de trabalho e a reprodução atrofiada desta. Nesse caso, o capital, ao encurtar o tempo de vida útil e de vida total do trabalhador, apropria-se, no presente, dos anos futuros de trabalho.

O prolongamento da força de trabalho se dá não só na sobrejornada, mas também no deslocamento. Trabalhadores periféricos tendem a longos trajetos e salários que não cobrem o custo da moradia (daí a opção por longínquas periferias). Desse modo, além de a proximidade com o trabalho ser dificultada, o transporte público não é satisfatório e o custo das

${ }^{4}$ Ver: Santana (2013). 


\section{meVistg am paltg}

\} INSURGÊNCIA E CONSERVADORISMO - SILVA, M. S. \}

DOI 10.12957/REP.2017.30377

horas do trajeto não é repassado para os salários. O trabalho intenso e a pressão sobre o trabalhador, tanto no que se refere ao cumprimento de metas, quanto à insegurança do emprego, faz com que o desgaste, físico e mental, seja exacerbado, sem as contrapartidas salariais ou dos serviços públicos necessários para a reprodução e manutenção cotidianas do trabalhador.

Nesse sentido, a reprodução atrofiada da força de trabalho influencia tanto a inadaptação aos imperativos das instituições modernas, quanto impele aos trabalhadores um grau de cidadania que impulsiona a luta diária pela subsistência. Assim, a tese de Marini (apud SANTANA, 2013) não invalida a de Holston (2009, 2013) ou de Souza (2003); pelo contrário, complementa-as e ajuda a explicá-las, na medida em que problematiza a reprodução da vida material dos trabalhadores, em sua maioria pobres.

Em países em que a superexploração do trabalho é a regra, em geral, a estrutura social é historicamente frágil. Neste contexto de fragilidade social, há um superdimensionamento da lei (como obrigação, e não como direitos) e da violência, antitéticas a uma cidadania substantiva plena. A nosso ver, dois aspectos, dentre outros, corroboram para a argumentação da relação paradoxal entre capitalismo e cidadania no Brasil, a saber, a imbricação hierárquica entre economia e política em uma sociedade; e as questões estruturais do Estado capitalista, somadas à formação social brasileira - que, mesmo partindo daquele, ressignifica-o.

\section{Os limites à cidadania insurgente}

Francisco de Oliveira (2007) argumenta que o mercado - ou a ideia de mercado - faz com que, ideologicamente, os agentes políticos se tornem secundários nas decisões que afetam o cotidiano das pessoas. Os entes jurídicos, como as empresas, dominam o cenário institucional estatal, influenciando, através de "lobbys", a distribuição de "direitos" que constitucionalmente deveriam ser garantidos e efetivados. A política partidária e os próprios governos que, dentro dos limites da representatividade, são democraticamente eleitos, estão subsumidos pela pressão econômica: “A empresa econômica, que já era o centro da concentração/centralização do capital, assume cada vez mais o centro da política" (OLIVEIRA, 2007, p. 288).

A política, nesses termos, continua viva, desde que foi inventada. Porém, institucionalmente não é o autêntico jogo das forças políticas constituintes de determinada sociedade que decide os rumos, mas é um jogo de cartas marcadas pelo interesse econômico, ou seja, o econômico anula o político. Oliveira (2007, p. 290) toma como exemplo a instituição Banco Central como um dos representantes econômicos que anulam a política: 
O Banco Central praticamente não presta contas a ninguém, a nenhuma instância da representação popular ou federativa; está, na prática, autonomizado, pois o próprio ministério da fazenda comparece o Copom que é a instância que decide sobre a taxa de juros básica - em igualdade de condições com os demais membros. Opera o Banco Central por meio de consultas com experts do mercado financeiro, principalmente altos executivos dos grandes bancos, e deste círculo estreito estão excluídos quaisquer outros cidadãos, individualmente ou em representação de classes.

Se decisões econômicas que determinam o rumo das vidas dos cidadãos são tomadas sem a participação política efetiva destes, com a justificativa de que são decisões "técnicas", a cidadania se faz irrelevante ante a força do mercado. As pessoas se tornam menos importantes do que os interesses econômicos. Decisões do Banco Central brasileiro, por exemplo, influenciam o nível de desemprego do país, os investimentos em Educação, Saúde, etc., não devendo, portanto, ser decisões estritamente técnicas, como se o mundo fosse regido pela técnica e não por pessoas, pelas relações estabelecidas entre elas. Neste contexto, a exceção - ou o que deveria ser - se impõe como regra:

Todas as políticas são ditadas pela excepcionalidade [...]. O Bolsa-Família é a exceção do salário, insuficiente, que não pode ser melhorado pelo monitoramento das instituições da 'polícia' mundial; o mutirão é a exceção da moradia, que não pode ser mercadoria vendida porque o salário é insuficiente; o Prouni é a exceção da universidade pública, substituída por um simulacro de universidade privada para os pobres, com subsídio federal; o PCC em São Paulo e o TCC no Rio são as exceções, gângsteres como não poderia deixar de ser, da segurança pública e do desmantelamento do poder repressivo do Estado Brasileiro. A lista seria longa e enfadonha. Trata-se de um Estado de Exceção. E quem é o soberano que decide o Estado de exceção? O mercado. (OLIVEIRA, 2007, p. 294-295).

Apesar disso, Francisco de Oliveira (2007) enxerga na política o elemento fundamental para a garantia e efetivação de direitos, em um contexto no qual o capital cada vez mais se impõe como atmosfera geral, regulando as relações sociais. A dimensão econômica ganha relevância e, consequentemente, aqueles que têm maior poder econômico se utilizam dessa prerrogativa para "garantir" seus direitos e reivindicar outros (OLIVEIRA, 2007, p. 283). Aos que não possuem esse poder econômico, resta a política. É neste ponto que a análise de Francisco de Oliveira (2007) se aproxima da de Holston $(2009$, 2013), a diferença principal está no estabelecimento de limites histórico-sociais para este e histórico-socioestruturais para aquele.

Esta diferenciação tem um peso grande na emergência de uma cidadania popular, já que a noção formal de justiça é atrelada ao poder econômico, e, portanto, torna-se uma barreira a ser rompida por meio da 


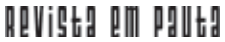

\} INSURGÊNCIA E CONSERVADORISMO - SILVA, M. S. \}

DOI 10.12957/REP.2017.30377

organização e pressão política dos movimentos sociais. Do mesmo modo, a noção mítica de cidadania política é atrelada ao sufrágio, isto é, à capacidade e possibilidade de votar e ser votado, tipo ideal de uma democracia representativa. T. H. Marshall entende que, segundo Saes (2001, p. 380)

[...] a cidadania política na sociedade industrial moderna ou contemporânea (nós diríamos, sociedade burguesa ou capitalista) designa a participação do Povo - isto é, dos indivíduos que o compõem - no exercício do poder político. Tal participação concretiza-se, segundo Marshall, como exercício efetivo, por parte do Povo, do direito de escolher os seus governantes. E o exercício efetivo desse direito implica, de um lado, a existência de um processo eleitoral autêntico, supervisionado por instituições judiciárias independentes, que garantam a correspondência entre os resultados das eleições e a vontade eleitoral da maioria social; de outro lado, a existência de governantes que de fato governem, o que supõe a presença de um Parlamento forte, efetivamente participante na tomada das grandes decisões nacionais.

O tipo ideal em questão não diz nada sobre e nem considera a dinâmica excludente do Estado capitalista, ou sequer problematiza que a influência popular é pequena nas decisões macropolíticas ou macroeconômicas. A pressão que geralmente exercem os meios de comunicação visa a tal ou tal parlamentar, no sentido de constrangê-lo para as próximas eleições. Ou seja, os interesses, quando não são escusos, são movidos pela coação.

Nesse sentido, a cidadania insurgente é, talvez, a novidade popular para responder ao Estado de direito que supõe a liberdade civil seletiva. Ora, direitos civis são conquistas dos trabalhadores (ao contrário do que costuma se aventar), assim como as liberdades políticas. Porém, dada sua distribuição desigual entre as classes sociais, os mais pobres necessariamente se insurgem; entretanto, no cômputo geral, é como se fosse uma conquista da sociedade como um todo, ou pior, benesses das classes dominantes.

Vemos, portanto, que a subsunção da política pela economia implica limites à cidadania popular vinculada ao poder econômico dos agentes, bem como ao peso desse poder no arcabouço legal. Neste sentido, a luta pela reprodução imediata da vida, desacompanhada de uma visão mais ampla e prospectiva da luta de classes, não é necessariamente uma escolha individual dos trabalhadores, mas uma imposição estrutural do sistema capitalista, que se corporifica também na natureza do Estado.

Outro aspecto importante como limite à cidadania insurgente popular, ou os limites estruturais relacionados à natureza do Estado capitalista, foi bem desenvolvido por David Harvey (2006) na sua leitura da teoria marxista do Estado, que se tornou, inclusive, título do ensaio. $\mathrm{O}$ argumento central é de que o Estado cumpre um papel fundamental como apoio ao modo capitalista de produção, executando tarefas básicas sem as quais este não funcionaria (HARVEY, 2006, p. 79). 
O Estado surge da contradição entre interesses públicos e privados, situando-se apenas aparentemente acima (como mediador e regulador) das classes. Essa relação Estado e sociedade gera a necessidade de o primeiro, do ponto de vista ideológico, reforçar a aparência universalista com instituições que discursivamente reforçam o "interesse geral", em detrimento do interesse de classe:

No modo capitalista de produção, as relações de troca originam, portanto, noções específicas a respeito do 'indivíduo', da 'liberdade', da 'igualdade', dos 'direitos', da 'justiça' e etc. Marx observou que tais conceitos normalmente proporcionam os brados ideológicos nos comícios de todas as revoluções burguesas. (HARVEY, 2006, p. 83).

O Estado tem, portanto, a função regulatória, mas age a partir do interesse da classe que impõe sua hegemonia na luta de classes, adaptando suas instituições, formais ou não, às transformações e necessidades da acumulação do capital. Na medida em que determinada forma de acumulação vem à tona, aqueles objetivos de um capitalismo mais "humano" se convertem em "[...] objetivos de eficiência e racionalidade do mercado, com toque de muito socialismo para os ricos, auxílio financeiro para empresas e instituições financeiras pouco sólidas e etc." (HARVEY, 2006, p. 77).

No contexto das lutas por moradias, por exemplo, o Estado aparece como o ente normativo que geralmente age contra a cidadania insurgente, adequando as garantias constitucionais às prerrogativas das classes abastadas. Contudo, cabe perguntar: o que é mais importante? O direito à moradia ou o direito à propriedade? Invariavelmente a noção hierárquica entre um e outro direito se dá pelo poder econômico.

\section{Considerações finais}

Holston $(2009$, 2013), ao não fazer a crítica ao capitalismo, remete o "emaranhado" da cidadania insurgente com a cidadania diferenciada, ao desenvolvimento histórico no Brasil. O que está correto, porém, se esquece de problematizar a busca incessante pelos interesses privados, traço característico do capitalismo, que é potencializado em tempos de expansão do livre mercado, causando esse estranhamento.

O estranhamento choca-se com o reconhecimento. Como o primeiro se relaciona principalmente com o paradoxo individualismo/individualidade - em que individualismo nega individualidade, na medida em que é ensimesmado e não se apropria de forma plena da riqueza social "espiritual", isto é, da cultura no sentido mais amplo -, ele se emaranha com o reconhecimento das potencialidades, dos direitos, etc., mas o fragmenta e o reduz ao específico: ao lugar, à comunidade, ao grupo. Desse conflito emerge tanto a cidadania substantiva, que reconhece e combate a 
opressão, posicionando-se no conflito, quanto a cidadania formal, que tende a reproduzir, em outras instâncias, a opressão, negando o conflito.

Concluímos, portanto, que a cidadania insurgente é, de fato, uma inovação democrática e um lampejo de cidadania substantiva, por isso deve ser considerada, compreendida e potencializada. Contudo, para além disso, é importante também compreender seus limites, não só histórico-sociais, mas também aqueles impostos pela base produtiva (o capitalismo), para não transformá-la em algo edênico, e, por consequência, estéril. 


\section{Referências}

HARVEY, D. A produção capitalista do espaço. São Paulo: Annablume, 2006. HOLSTON, J. Espaços de cidadania insurgente. In: ARANTES, A. A. (Org.). Revista do Patrimônio Histórico e Artístico Nacional, n. 24, 1996.

. Insurgent citizenship in an era of global urban peripheries. City \& Society, v. 21, n. 2, 2009.

. Cidadania insurgente: disjunções da democracia e da modernidade no Brasil. São Paulo: Companhia das Letras, 2013.

LEFEBVRE, H. O direito à cidade. 4ae ed. São Paulo: Centauro, 2006.

OLIVEIRA, F. Capitalismo e política: um paradoxo letal. In: NOVAES, A. (Org.). O esquecimento da política. Rio de Janeiro: Agir, 2007.

SAES, D. A. M. A questão da evolução da cidadania política no Brasil. Estudos Avançados, São Paulo, v.15, n. 42, maio/ago. 2001.

SANTANA, P. M. Dependência e superexploração do trabalho no capitalismo contemporâneo. Brasília: Ipea/ABET, 2013.

SOARES, M. C. Representações, jornalismo e a esfera pública democrática. São Paulo: Editora Unesp, 2009.

SOUZA, J. A construção social da subcidadania: para uma sociologia política da modernidade periférica. Belo Horizonte: Editora da UFMG, 2003.

TAVOLARO, S. B. F.; TAVOLARO, L. G. M. A cidadania sob o signo do desvio: para uma crítica da "tese da excepcionalidade brasileira". Revista Sociedade e Estado, v. 25, n. 2, maio/ ago. 2010.

THERBORN, G. Why and how place matters. In: GOODIN, R. E. (Ed.). The oxford handbook of political science. Oxford: Oxford University Press, 2011.

. Novas massas? Classe média, consumismo e classes sociais na crítica a ordem capitalista. 2014. Disponível em: <http://piaui.folha.uol.com.br/ materia/novas-massas>. Acesso em: 22 fev. 2016.

VAINER, C. Entrevista. 2011. Disponível em: <http://www.epsjv.fiocruz.br/ upload/EdicoesRevistaPoli/R17.pdf>. Acesso em: 3 mar. 2016.

Recebido em 07 de abril de 2017.

Aprovado para publicação em 14 de julho de 2017.

DOI 10.12957/rep.2017.30377

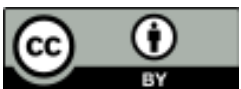

A Revista Em Pauta: Teoria Social e Realidade Contemporânea está licenciada com uma Licença Creative Commons Atribuição 4.0 Internacional. 